\title{
Ceftriaxone treatment failure of pharyngeal gonorrhoea verified by international recommendations, Sweden, July 2010
}

M Unemo (magnus.unemo@orebroll.se) ${ }^{1}$, D Golparian¹, A Hestner ${ }^{2}$

1. Swedish Reference Laboratory for Pathogenic Neisseria, Department of Laboratory Medicine, Microbiology, Örebro University Hospital, Örebro, Sweden

2. Department of Dermatology and Venereology, Kärnsjukhuset, Skövde, Sweden

Citation style for this article:

Unemo M, Golparian D, Hestner A. Ceftriaxone treatment failure of pharyngeal gonorrhoea verified by international recommendations, Sweden, July 2010 . Euro Surveill. 2011;16(6):pii=19792. Available online: http://www.eurosurveillance.org/ViewArticle.aspx?Articleld=19792

Article published on 10 February 2011

This report describes one case of verified treatment failure of pharyngeal gonorrhoea using ceftriaxone in Sweden. Previous reports described verified treatment failure of urogenital gonorrhoea using the internationally recommended first-line drug cefixime, but not with ceftriaxone, the last remaining option for empirical treatment of gonorrhoea. Enhanced awareness of clinical failures, pharmacodynamic considerations, follow-up and test of cure, adherence to appropriate case management and treatment guidelines as well as verification/falsification of presumed clinical treatment failures should be emphasised worldwide.

\section{Case report}

In late July 2010, a Swedish heterosexual man in his early $20 s$ presented to a primary healthcare clinic in Sweden (on day 1) with symptoms and signs of urogenital and pharyngeal infection (Table). Four days earlier he had had protected vaginal intercourse and unprotected oral sex with a casual female partner in Japan. Polymerase chain reaction (PCR) analysis of DNA obtained from his urine sample was positive for Neisseria gonorrhoeae (using Cobas 4800 PCR, Roche Molecular Systems). He was given out-of-date empirical treatment for gonorrhoea (amoxicillin) and referred to a clinic for sexual transmitted infections. On day 12, he presented to this clinic with resolved urogenital symptoms, but pharyngeal inflammation was still present. Although microscopy, culture and PCR analysis of urogenital samples were negative for $N$. gonorrhoeae, a pharyngeal culture was $N$. gonorrhoeae positive and he was therefore given (day 26) ceftriaxone ( $250 \mathrm{mg}$ ), an extended-spectrum cephalosporin (ESC), which is an internationally recommended first-line treatment for gonorrhoea. On day 36, follow-up examination and test of cure showed that the pharyngeal culture remained positive, the pharyngeal inflammation persisted, and he was given 500 mg ceftriaxone on day 43. On day 50, he returned with persisting positive pharyngeal culture and pharyngeal inflammation. He was subsequently administered one dose of $1 \mathrm{~g}$ ceftriaxone intraveneously (on day 71) and was also referred to an otorhinolaryngologist, who did not identify any pharyngeal abnormalities. On days 85 and 92, two follow-up examinations showed no visible signs of infection and two pharyngeal cultures were negative for $N$. gonorrhoeae. The patient reported no sexual contacts from day one until the $N$. gonorrhoeae culture results were negative (Table).

\section{Characterisation of $N$. gonorrhoeae isolates (before and after treatment)}

All N. gonorrhoeae isolates were species-confirmed by sugar utilisation test and Phadebact Monoclonal GC Test (Pharmacia Diagnostics).

All pre- and post-treatment isolates were indistinguishable using serovar determination (Bpyvut), fulllength DNA sequencing of the $N$. gonorrhoeae porB gene, and $N$. gonorrhoeae multiantigen sequence typing (NG-MAST; ST2958), performed as previously described [1]. Using Etest (AB bioMérieux, Sweden), all isolates displayed a ceftriaxone minimum inhibitory concentration (MIC) of 0.125 or $0.25 \mathrm{mg} / \mathrm{L}$ (Table), and overall indistinguishable antibiograms (ampicillin $2 \mathrm{mg} / \mathrm{L}$, cefixime $0.5 \mathrm{mg} / \mathrm{L}$, spectinomycin $12 \mathrm{mg} / \mathrm{L}$, azithromycin $0.5 \mathrm{mg} / \mathrm{L}$, ciprofloxacin $132 \mathrm{mg} / \mathrm{L}$, gentamicin $4 \mathrm{mg} / \mathrm{L}$ ) and were beta-lactamase negative. According to the ceftriaxone breakpoints stated by the European Committee on Antimicrobial Susceptibility Testing (EUCAST) [2], the ceftriaxone MICs of these isolates were equal to or slightly above the resistance breakpoint $(>0.125 \mathrm{mg} / \mathrm{L})$. Sequencing of the $N$. gonorrhoeae penA, mtrR and porB1b alleles, which are known to contribute to the resistance to ESCs, was performed as previously described [3]. All isolates contained an identical penA mosaic allele that has been correlated with treatment failure using oral ESCs in Japan and recently in Norway [4-6], and had $m \operatorname{trR}$ and pen $B$ alterations that enhance further the ESC MIC $[7,8]$.

\section{Background}

Gonorrhoea remains a public health concern globally. $N$. gonorrhoeae has developed resistance to all 
antimicrobials previously used as first-line treatments [4]. Furthermore, susceptibility to the currently internationally recommended first-line ESCs that are the last remaining treatment options - cefixime (oral) and ceftriaxone (injectable) - has rapidly decreased worldwide [4]. Verified treatment failures using cefixime have already been reported from Japan [5] and recently also from Europe [6]. Treatment failures of urogenital gonorrhoea using ceftriaxone have still not been verified, but two cases of clinical failure in the treatment of pharyngeal gonorrhoea were reported in Australia [9]. However, as the ceftriaxone MICs of these gonococcal isolates were low (0.016 and $0.032 \mathrm{mg} / \mathrm{L})$, these clinical failures were unlikely to have been due to bacterial resistance. Rather it was probably due to the known difficulties in treating pharyngeal gonorrhoea compared with urogenital infection. Due to pharmacodynamic parameters, few antimicrobial drugs can reliably cure more than $90 \%$ of pharyngeal gonorrhoea infections [4,10-12]. Worryingly, the first $N$. gonorrhoeae strain displaying high-level ceftriaxone resistance has now been isolated in Japan [13].

\section{Discussion and conclusion}

This study describes one case of clinical failure of pharyngeal gonorrhoea using internationally recommended first-line treatment ceftriaxone, which is the last remaining treatment option. The treatment failure was rigorously confirmed in accordance with the World
Health Organization (WHO) recommendations [4], i.e. a detailed clinical history was recorded and the likelihood of re-exposure and reinfection was excluded as much as possible. Accordingly, the patient reported no sexual contact after his initial one in Japan (place of exposure) and the gonococcal sequence type identified, ST2958, has previously been found only in Australia [14]. Furthermore, pre- and post-treatment isolates were phenotypically and genetically indistinguishable using highly discriminatory genetic epidemiological typing, MICs of ceftriaxone were substantially enhanced, and the isolates contained resistance determinants causing enhanced ceftriaxone MICs.

We may now be reaching the ceftriaxone MICs for which complete bacterial eradication in pharynx, and soon in the urogenital tract, will be impossible in rare cases. According to Monte Carlo simulations [15], a $250 \mathrm{mg}$ dose of ceftriaxone results in median times of free ceftriaxone above the MIC ( $f$ T>MIC) of only $24.1 \mathrm{~h}$ (range: $10.5-52.2 \mathrm{~h}$ ) and $15.4 \mathrm{~h}$ (range: $5.3-34.3 \mathrm{~h}$ ) for the MICs of $0.125 \mathrm{mg} / \mathrm{L}$ and $0.25 \mathrm{mg} / \mathrm{L}$, respectively, which were detected in the present study. Such ceftriaxone MICs may cause rare treatment failures, which most likely will be more frequent when treating pharyngeal gonorrhoea, for which the $f$ T>MIC of accessible ceftriaxone will be even shorter. Such treatment failures may already be occurring but not being identified due to rare use of test of cure and also because

\section{TABLE}

Details of verified clinical failure of one case of Neisseria gonorrhoeae pharyngeal infection using internationally recommended first-line ceftriaxone treatment of gonorrhoea, Sweden, 2010

\begin{tabular}{|c|c|c|c|c|c|c|c|}
\hline \multirow{2}{*}{$\begin{array}{l}\text { Type of healthcare } \\
\text { clinic (day of } \\
\text { presentation) }\end{array}$} & \multirow{2}{*}{$\begin{array}{l}\text { Symptoms } \\
\text { (signs) }\end{array}$} & \multicolumn{2}{|c|}{ Diagnostic test } & \multicolumn{2}{|c|}{$\mathrm{MIC}(\mathrm{mg} / \mathrm{L})^{\mathrm{a}}$} & \multirow[b]{2}{*}{ NG-MAST ${ }^{b}$} & \multirow{2}{*}{$\begin{array}{c}\text { Treatment } \\
\text { (day administered) }\end{array}$} \\
\hline & & $\begin{array}{c}\text { Positive } \\
\text { (type of sample) }\end{array}$ & $\begin{array}{c}\text { Negative } \\
\text { (type of sample) }\end{array}$ & Ampicillin & Ceftriaxone & & \\
\hline STI (12) & $\begin{array}{c}- \\
\text { (inflammation in } \\
\text { pharynx) }\end{array}$ & $\begin{array}{c}\text { Culture } \\
\text { (pharyngeal) }\end{array}$ & $\begin{array}{l}\text { Microscopy and } \\
\text { culture } \\
\text { (urethral) } \\
\text { PCR (urine) }\end{array}$ & 2 & 0.125 & $\mathrm{ST} 2958$ & $\begin{array}{c}\text { Ceftriaxone } \\
\text { One dose of } 250 \mathrm{mg} \text {, } \\
\text { intramuscular administration } \\
(\text { day } 26)\end{array}$ \\
\hline STI (36) & $\begin{array}{l}- \\
\text { (inflammation in } \\
\text { pharynx) }\end{array}$ & $\begin{array}{c}\text { Culture } \\
\text { (pharyngeal) }\end{array}$ & NA & 2 & 0.125 & ST2958 & $\begin{array}{c}\text { Ceftriaxone } \\
\text { One dose of } 500 \mathrm{mg}, \\
\text { intramuscular administration } \\
\text { (day 43) }\end{array}$ \\
\hline STI (50) & $\begin{array}{l}- \\
\operatorname{(inflammation~in~}_{\text {pharynx }^{c}}^{c}\end{array}$ & $\begin{array}{c}\text { Culture } \\
\text { (pharyngeal) }\end{array}$ & NA & 2 & 0.25 & ST2958 & $\begin{array}{c}\text { Ceftriaxone } \\
\text { One dose of } 1 \mathrm{~g}, \\
\text { intravenous administration } \\
(\text { day } 71)\end{array}$ \\
\hline STI (85 and 92) & $\begin{array}{l}- \\
(-) \\
\end{array}$ & NA & $\begin{array}{c}\text { Culture } \\
\text { (pharyngeal) }\end{array}$ & NA & NA & NA & NA \\
\hline
\end{tabular}

MIC: minimum inhibitory concentration; NA: not applicable; PCR: polymerase chain reaction; STI: sexually transmitted infections.

${ }^{a}$ Etest was used and all MIC values were rounded up to whole MIC dilutions.

${ }^{b}$ Neisseria gonorrhoeae multiantigen sequence typing of cultured $N$. gonorrhoeae post-treatment isolates.

c The patient was also referred to an otorhinolaryngologist, who did not identify any pharyngeal abnormalities. 
azithromycin [16] is administered to many gonorrhoea patients, due to suspicion of concomitant chlamydial infection $[4,15]$.

Notably, the current case presented initially to a primary healthcare clinic with urogenital and pharyngeal symptoms. Despite the pharyngeal pain, however, no pharyngeal sample was taken and, in addition, he was given out-of-date treatment. It is therefore crucial that national case management and treatment guidelines are up to date and strictly adhered to at all levels of the healthcare system, including at the primary level.

In conclusion, one case of clinical failure using standard ceftriaxone treatment for pharyngeal gonorrhoea has been verified in Sweden. An increased awareness of future clinical failures (including those using ceftriaxone), more frequent test of cure, and strict adherence to appropriate case management and treatment guidelines as well as verification/falsification of presumed treatment failures should be emphasised worldwide. Importantly, treatment of pharyngeal gonorrhoea poses a considerable challenge as it is harder to treat than urogenital infection, is frequently asymptomatic and acts as a reservoir for infection and emergence of resistance [4]. Accordingly, it is important not only to collect information regarding clinical anamnesis, but also on patients' sexual practices and, if indicated, subsequently take extragenital samples as well. Finally, there is a need for studies on the pharmacokinetics/pharmacodynamics of antimicrobial drugs in the pharynx, and new treatment options (single or in combination) as well as new drug development for gonorrhoea treatment.

\section{References}

1. Unemo M, Sjöstrand A, Akhras M, Gharizadeh B, Lindbäck E, Pourmand N, et al. Molecular characterization of Neisseria gonorrhoeae identifies transmission and resistance of one ciprofloxacin-resistant strain. APMIS. 2007;115(3):231-41.

2. European Committee on Antimicrobial Susceptibility Testing (EUCAST). European Society of Clinical Microbiology and Infectious Diseases. Clinical breakpoints. EUCAST. [Accessed 8 Feb 2011]. Available from: http://www.eucast.org/ clinical_breakpoints/

3. Unemo M, Fasth O, Fredlund H, Limnios A, Tapsall J. Phenotypic and genetic characterization of the 2008 WHO Neisseria gonorrhoeae reference strain panel intended for global quality assurance and quality control of gonococcal antimicrobial resistance surveillance for public health purposes. J Antimicrob Chemother. 2009;63(6):1142-51.

4. Tapsall JW, Ndowa F, Lewis DA, Unemo M. Meeting the public health challenge of multidrug- and extensively drugresistant Neisseria gonorrhoeae. Expert Rev Anti Infect Ther. 2009;7(7):821-34.

5. Yokoi S, Deguchi T, Ozawa T, Yasuda M, Ito S, Kubota Y, et al. Threat to cefixime treatment of gonorrhea. Emerg Infect Dis. 2007;13(8):1275-7.

6. Unemo M, Golparian D, Syversen G, Vestrheim DF, Moi H. Two cases of verified clinical failures using internationally recommended first-line cefixime for gonorrhoea treatment, Norway, 2010. Euro Surveill. 2010;15(47):pii=19721. Available from: http://www.eurosurveillance.org/ViewArticle. aspx?Articleld $=19721$

7. Lindberg R, Fredlund H, Nicholas R, Unemo M. Neisseria gonorrhoeae isolates with reduced susceptibility to cefixime and ceftriaxone: Association with genetic polymorphisms in penA, mtrR, porB1b, and ponA. Antimicrob Agents Chemother. 2007;51(6):2117-22
8. Zhao S, Duncan M, Tomberg J, Davies C, Unemo M, Nicholas R. Genetics of chromosomally mediated intermediate resistance to ceftriaxone and cefixime in Neisseria gonorrhoeae. Antimicrob Agents Chemother. 2009;53(9):3744-51.

9. Tapsall J, Read P, Carmody C, Bourne C, Ray S, Limnios A, et al. Two cases of failed ceftriaxone treatment in pharyngeal gonorrhoea verified by molecular microbiological methods. J Med Microbiol. 2009;58(Pt 5):683-7.

10. Moran JS. Treating uncomplicated Neisseria gonorrhoeae infections: is the anatomic site of infection important? Sex Transm Dis. 1995;22(1):39-47.

11. Newman LM, Moran JS, Workowski KA. Update on the management of gonorrhea in adults in the United States. Clin Infect Dis. 2007;44(Suppl 3):S84-101.

12. Workowski KA, Berman SM, Douglas JM Jr. Emerging antimicrobial resistance in Neisseria gonorrhoeae: urgent need to strengthen prevention strategies. Ann Intern Med. 2008;148(8):606-13.

13. Ohnishi M, Saika T, Hoshina S, Iwasaku K, Nakayama $\mathrm{S}$, Watanabe $\mathrm{H}$, et al. Ceftriaxone-resistant Neisseria gonorrhoeae, Japan. Emerg Infect Dis. 2011;17(1):148-9.

14. Neisseria gonorrhoeae Multi Antigen Sequence Typing (NG MAST). London: Imperial College London. [Accessed 8 Feb 2011]. Available from: http://www.ng-mast.net/

15. Chisholm SA, Mouton JW, Lewis DA, Nichols T, Ison CA, Livermore DM. Cephalosporin MIC creep among gonococci: time for a pharmacodynamic rethink? J Antimicrob Chemother. 2010;65(10):2141-8.

16. Sathia L, Ellis B, Phillip S, Winston A, Smith A. Pharyngeal gonorrhoea - is dual treatment the way forward? Int J STD AIDS. 2007;18(9):647-8. 